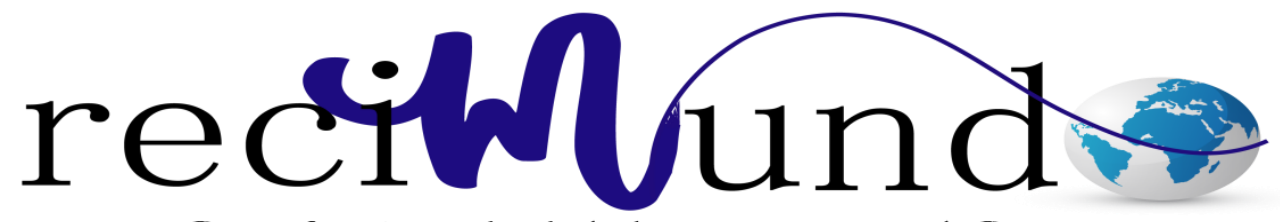

Revista Cientifica Mundo de la Investigación y el Conocimiento

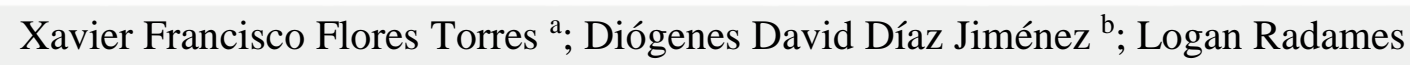
Berni Morán ${ }^{\mathrm{c}}$

La dolarización en el Ecuador

Revista Científica Mundo de la Investigación y el Conocimiento. Vol. 1 núm., 5, diciembre, 2017, pp. 601-624

DOI: 10.26820/recimundo/1.5.2017.601-624

Editorial Saberes del Conocimiento
a. Universidad de Guayaquil; xavier.florest@ug.edu.ec
b. Universidad de Guayaquil; diogenes.diazj@ug.edu.ec
c. Universidad de Guayaquil; logan.bemim@ug.edu.ec 


\section{La dolarización en el Ecuador}

Vol. 1, núm. 5., (2017)

Xavier Francisco Flores Torres; Diógenes David Díaz Jiménez; Logan Radames Berni Morán

\section{RESUMEN}

Este estudio se centra en la dolarización en el Ecuador, ya que es un tema de vital importancia, sobre todo porque es el segundo país que la adquirió, cuando el país adoptó una moneda extranjera que reemplazó a la moneda de origen, surgieron cambios drásticos; los cuales trajeron como consecuencias problemas económicos, sociales y políticos, debido a que pretendió dar un contundente cambio en orientación a la economía nacional, queriendo enderezar la estabilidad económica y el crecimiento económico del país.

Además aumentó la migración de los ecuatorianos a otros países, debido a que hubo pérdidas económicas e incluso incrementó la tasa de desempleo, causando inestabilidad económica a todos los ecuatorianos, pero los más afectados fueron la clase media, debido a que perdieron todos sus ahorros; y los únicos que se lucraron fueron el sector de la política porque sabían con anterioridad la modificación del sistema monetario del país y se anticiparon a las medidas comprando dólares y también lograron incrementar los niveles de productividad de las empresas.

Los objetivos de este cambio trascendental eran frenar la tremenda volatilidad y detener la creciente inflación que amenazaba en convertirse en hiperinflación, pero lo único que consiguieron fue un mayor decrecimiento económico en el país.

Luego de que se estabilizara la dolarización, el banco central, emprendió una amplia compaña a nivel nacional que buscaba explicar lo que es la dolarización, el por qué y el para que se hizo la dolarización, con el propósito de que la población conociera con amplitud la reforma económica y, por lo tanto, se pudiera identificar con ella.

Palabras Claves: Economía nacional, pérdidas económicas, desempleo, inestabilidad económica. 


\title{
La dolarización en el Ecuador
}

Vol. 1, núm. 5., (2017)

Xavier Francisco Flores Torres; Diógenes David Díaz Jiménez; Logan Radames Berni Morán

\begin{abstract}
This study focuses on dollarization in Ecuador, since it is a subject of vital importance, especially because it is the second country that acquired it, when the country adopted a foreign currency that replaced the currency of origin, drastic changes arose; which brought as consequences economic, social and political problems, because it intended to give a strong change in orientation to the national economy, wanting to straighten the economic stability and economic growth of the country.
\end{abstract}

Also increased the migration of Ecuadorians to other countries, because there were economic losses and even increased the unemployment rate, causing economic instability to all Ecuadorians, but the most affected were the middle class, because they lost all their savings; and the only ones that profited were the political sector because they knew beforehand the modification of the monetary system of the country and anticipated the measures buying dollars and also managed to increase the levels of productivity of the companies.

The objectives of this momentous change were to stop the tremendous volatility and stop the growing inflation that threatened to become hyperinflation, but the only thing they achieved was a greater economic decline in the country.

After the dollarization stabilized, the central bank undertook a broad national campaign that sought to explain what dollarization is, why and for what dollarization was done, with the purpose that the population knew widely. economic reform and, therefore, could be identified with it.

Keywords: National economy, economic losses, unemployment, economic instability. 


\section{La dolarización en el Ecuador}

Vol. 1, núm. 5., (2017)

Xavier Francisco Flores Torres; Diógenes David Díaz Jiménez; Logan Radames Berni Morán

\section{Introducción.}

La dolarización es el cambio de una moneda extranjera que adopta un país para su uso dándole de bajo a su moneda de origen, dicha moneda estadounidense reemplaza a la moneda de origen en todas sus funciones comerciales, reserva de valores y unidades de cuenta.

El Ecuador fue el segundo país que adquirió la dolarización en América latina, después del Salvador perdiendo la soberanía monetaria de dichos países. Esta modificación causo muchas acciones contraproducentes a nuestro país, porque era un sistema monetario casi desconocido donde existía la duda si era la solución para la crisis financiera del Ecuador de aquella época.

El dólar moneda estadounidense, que entro al Ecuador en 1999 donde le puso fin a la circulación del sucre que era la moneda de origen del Ecuador este cambio drástico trajo problemas económicos, sociales y políticos, el entonces presidente de la república del Ecuador el Abg. Jorge Jamil Mahuad él le puso inicio a la dolarización en el país de una manera oficial.

La dolarización conllevo al aumento de la migración de los ecuatorianos a otros países, la clase media fue la más perjudicada en aquella época al perder todos sus ahorros adquiridos a lo largo de su vida y también incremento considerablemente las tasas de desempleo provocando una inestabilidad económica a las familias ecuatorianas.

El sector de influencia política y económica fue el único que se lucro de la dolarización porque sabían con anterioridad la modificación del sistema monetario del país y se anticiparon a las medidas comprando dólares y también incrementaron los niveles de productividad de las empresas, ya que lograron reducir costos en especial los financieros. 


\section{La dolarización en el Ecuador}

Vol. 1, núm. 5., (2017)

Xavier Francisco Flores Torres; Diógenes David Díaz Jiménez; Logan Radames Berni Morán

\section{Reseña histórica de la dolarización en ecuador}

(Santos T. , 2015) afirma: "El 9 de enero de 2000, el presidente Jamil Mahuad, en medio de la mayor crisis económica de la historia del país, sorprendió a los ecuatorianos un domingo en la noche cuando en cadena nacional anunció que se adoptaba el dólar como moneda oficial. Moría el sucre y con él, la devaluación y la inflación que habían sumido a más de la mitad de la población en la pobreza. Ecuador era el segundo país latinoamericano, después de Panamá que llevaba un siglo usando el dólar, en aplicar la innovadora medida. Poco después le seguiría El Salvador y se creía entonces que la dolarización se expandiría por la región".

El anuncio fue un triunfo personal para los economistas ecuatorianos que trabajaron intensamente en promover la dolarización a pesar de la resistencia del propio Mahuad y de su equipo. Joyce de Ginatta, presidenta de la Cámara de la Pequeña Industria, lideró un movimiento llamado Foro Económico, que proponía la dolarización y al que se unieron profesores universitarios como Franklin López Buenaño y Pablo Lucio Paredes, expertos monetaristas como Carlos Julio Emanuel, y economistas liberales como Dora de Ampuero, la fundadora del Instituto Ecuatoriano de Economía Política. Menos conocido, pero importante, es el papel que tuvieron dos economistas estadounidenses y uno venezolano, muy influyentes en el Congreso y el Departamento del Tesoro de Estados Unidos, que recorrían el mundo promoviendo la convertibilidad y la dolarización.

(Marco, 2008) Afirma: “A principios del año 2000, el estado nacional estableció la dolarización oficial de la economía del ecuador. Entre los objetivos de este cambio trascendental estaban frenar la tremenda volatilidad cambiaria, detener la creciente inflación que amenazaba en convertir en hiperinflación, reactivar el aparato productivo que se había mantenido estancado 


\section{La dolarización en el Ecuador}

Vol. 1, núm. 5., (2017)

Xavier Francisco Flores Torres; Diógenes David Díaz Jiménez; Logan Radames Berni Morán

durante los últimos 20 años y sufrió mayor decrecimiento de la historia económica nacional durante 1999, enviar señales para 1 inversión productiva, y dar muestra de la existencia de objetivos de disciplina y cumplimiento de las obligaciones a la comunidad internacional" (p.222 y 223).

En general la dolarización oficial pretendió dar una vuelta de timón de 180 grados en la orientación de la economía nacional, de manera que el país se encauzara por los senderos de la estabilidad y el crecimiento, en donde fue desconocido en los años 80 y 90.

La dolarización oficial no solo ha implicado una modificación del régimen cambiario, si no que ha significado el establecimiento al menos tres pilares sustanciales para la estabilidad y el crecimiento: cambio del sistema monetario; promoción del equilibrio macroeconómico y puesta en práctica de reformas estructurales.

En el orden jurídico, la dolarización oficial del ecuador tiene como base legal a la ley de transformación económica que introduce cambios en el ámbito financiero y fiscal, dicha ley otorga la ejecución del sistema de dolarización al banco central del Ecuador, suprimiendo la potestad que esta entidad tenia de ser prestamista de última instancia, así como su actuación directa en la economía a través de la política monetaria.

\section{Fijador del tipo de cambio}

(Marco, 2008) Afirma: “Una vez prolongado el decreto mediante el cual se establecía la dolarización oficial de la economía ecuatoriana, el banco central procedió a la fijación del tipo de cambio de canje de los sucres existentes por dólares. Se determinó una cotización de 25.000sucres por dólar, resultante aproximada de la división de la base monetaria amplia 


\section{La dolarización en el Ecuador}

Vol. 1, núm. 5., (2017)

Xavier Francisco Flores Torres; Diógenes David Díaz Jiménez; Logan Radames Berni Morán (especie monetaria en circulación + depósitos de los bancos en el banco central + bonos de estabilización monetaria) y la reserva monetaria internacional disponible para la dolarización" (p.225).

\section{Acuñación de monedas}

(Marco, 2008) afirma: "El banco central del Ecuador contrato 1 acuñación de una nueva familia de monedas con características en cuanto a tamaño, peso, forma y valor similares a las monedas fraccionarias de dólar de los Estados Unidos.

Se emitieron:

150 millones de monedas de un centavo

152 millones de monedas de 5 centavos

199 millones de monedas de 10 centavos

104 millones de monedas de 25 centavos

59 millones de monedas de 50 centavos

Para un total de 664 millones de monedas que equivalen a 84.5 millones de dólares. Cabe resultar el hecho de que esta emisión de dinero fraccionario es absolutamente convertible y tiene respaldo total, de manera que dos monedas de centavos emitidas por el banco central del Ecuador pueden ser cambiadas en cualquier lugar de la república por un billete de un dólar en los Estados Unidos" (p.225).

\section{Marco conceptual}




\section{La dolarización en el Ecuador}

Vol. 1, núm. 5., (2017)

Xavier Francisco Flores Torres; Diógenes David Díaz Jiménez; Logan Radames Berni Morán

(Marco, 2008) Afirma: "La vigencia legal de la dolarización en el ecuador, el banco central, institución encargada el nuevo régimen monetario, emprendió una amplia compaña a nivel nacional que buscaba explicar lo que es la dolarización, el por qué y el para que se hizo la dolarización y el uso del dólar. Esto llevo a cabo a través de conferencia en gremios, recitos, cámaras de la producción y de comercio, universidades, unidades educativas de todo nivel, ministerios, mercados populares oficinas gubernamentales etc. En la compañía difusión, a más de las conferencias señaladas, se utilizaron todos los medios existentes, lo

Cual permitió que la población conociera con amplitud la reforma económica y, por lo tanto, se pudiera identificar con ella" (p.226).

(Axel Gaztambide 2010) afirma: "De la dolarización parcial de los años 1980 y 1990 a la dolarización integral en el 2000 En un contexto de inflación elevada y duradera, los agentes se desvían de la moneda nacional ya que su poder adquisitivo en bienes y servicios disminuye. Por ejemplo, para un activo monetario (no remunerado24) en moneda nacional de una unidad, la pérdida de poder adquisitivo en términos de bienes y servicios" (p.30).

\section{Ventajas de la dolarización en el ecuador}

$\checkmark \quad$ La inflación, que es el ritmo del incremento de precios, se reducirá a un solo dígito (por debajo del 10\%) a mediano plazo. En el año de transición, que es el 2000, la inflación inclusive crecerá, por el proceso de nivelación de los precios. 


\section{La dolarización en el Ecuador}

Vol. 1, núm. 5., (2017)

Xavier Francisco Flores Torres; Diógenes David Díaz Jiménez; Logan Radames Berni Morán

$\checkmark \quad$ Las tasas de interés internas se ajustarán a los niveles internacionales, se ubicarán en alrededor del 14\% para los créditos y en el 8\% para los depósitos.

$\checkmark \quad$ Se recuperará el ahorro, porque se elimina el riesgo de la devaluación, y se facilitará el financiamiento porque es más factible acceder a créditos en el sistema financiero.

$\checkmark \quad$ Aumento de la productividad de las empresas, ya que podrán reducir sus costos, en especial los financieros.

$\checkmark \quad$ Beneficia a los asalariados, a los empleados; por cuanto no se deteriora la capacidad adquisitiva de sus sueldos, cuando, como dicen los analistas económicos: "se sincere la economía".

$\checkmark \quad$ Facilita la planificación a largo plazo, pues permite la realización de cálculos económicos que hacen más eficaces las decisiones económicas.

$\checkmark \quad$ Se genera disciplina fiscal, en tanto el gobierno no puede emitir dinero. La corrección del déficit fiscal solo se puede hacer mediante financiamiento, vía préstamos o impuestos.

\section{Desventajas de la dolarización.}

$\checkmark \quad$ Pérdida del señoreaje que es la diferencia que existe entre el costo intrínseco del papel, más su impresión como billete y el poder adquisitivo del mismo, al dolarizar la economía, significará la pérdida del señoreaje para el estado ecuatoriano, según datos del banco central 


\section{La dolarización en el Ecuador}

Vol. 1, núm. 5., (2017)

Xavier Francisco Flores Torres; Diógenes David Díaz Jiménez; Logan Radames Berni Morán

significará entre \$ 35 y 40 millones; no obstante, las autoridades económicas está manteniendo conversaciones con las autoridades del tesoro de los estados unidos y de la reserva federal para que el señoreaje sea compartido.

$\checkmark \quad$ Pérdida de flexibilidad en la política monetaria, en un sistema monetario dolarizado el gobierno nacional no puede devaluar la moneda o financiar el déficit presupuestario mediante la creación de inflación porque no puede emitir dinero.

$\checkmark \quad$ Problemática de shocks externos.

$\checkmark \quad$ Los productos costarán más, pero luego de un proceso de adaptación, habrá una estabilidad.

$\checkmark \quad$ El costo por una sola vez, de convertir precios, programas de computación, cajas registradoras y máquinas vendedoras automáticas de moneda doméstica a moneda extranjera.

$\checkmark \quad$ Costo de perder un banco central local como prestamista de última instancia, en especial para los bancos ineficientes. Para las cooperativas de ahorro y crédito, jamás ha existido un apoyo, más bien nos van quitando ciertas ventajas competitivas (pagar el impuesto a la renta).

\section{Las negociaciones sobre la deuda externa del Ecuador entre 1982 y 1999}

(Gastambide, 2010) Afirma: "Durante las décadas de los 1980 y 1990, la deuda ecuatoriana es esencialmente una deuda soberana ya que a partir 1984 la deuda privada (25 por 


\section{La dolarización en el Ecuador}

Vol. 1, núm. 5., (2017)

Xavier Francisco Flores Torres; Diógenes David Díaz Jiménez; Logan Radames Berni Morán

ciento de la deuda externa total en 1982) hace el objeto de una sucretización a cargo del Estado" (p.40).

\section{La dolarización de los billetes}

(Gastambide, 2010) Afirma: "No hay un registro estadístico sobre la retención de billetes en dólares por parte del público. La mayor parte de los estudios sobre la dolarización parcial están confrontados a esta falta de datos sobre los billetes en dólares en circulación en la economía donde existe un proceso de dolarización parcial. Sin embargo, hay excepciones; el estudio más convincente está siendo el de Kamin y Ericsson (2003). Estos autores proponen una medida de los billetes dólares en circulación en Argentina entre 1988 y 1992. Para esto, utilizan estadísticas del departamento del Tesoro de los Estados Unidos10 que registró para Argentina, las operaciones individuales o de entidades que transportaron 10000 dólares hacia o fuera de los Estados Unidos. Una vez puesta una hipótesis sobre el importe inicial de billetes, proponen una medida cuantitativa de los billetes en dólares en circulación para el período estudiado. La medida propuesta puede criticarse desde tres puntos de vista" (p.56).

\section{La dolarización financiera}

(Gastambide, 2010) Afirma: "La dolarización financiera incluye todos los depósitos en dólares efectuados por un residente en el sistema bancario nacional o en el extranjero. Generalmente, la dolarización financiera hace referencia a los depósitos en dólares constituidos en el sistema bancario nacional. Sin embargo, en algunos casos y, en particular, en el Ecuador puede ser importante tener en cuenta los depósitos en dólares constituidos en los bancos en el extranjero. Pues hay que distinguir la "dolarización financiera exterior" (que corresponde a los 


\section{La dolarización en el Ecuador}

Vol. 1, núm. 5., (2017)

Xavier Francisco Flores Torres; Diógenes David Díaz Jiménez; Logan Radames Berni Morán

depósitos en dólares en el extranjero) y la "dolarización financiera interna" (correspondiendo a los depósitos en dólares en el sistema bancario nacional12)” (p.57).

\section{Valoración del estado de conservación de la moneda}

(Reyes, 2011)

Expresa: "Esto es uno de los aspectos más importantes al momento de determinar la valía de una moneda como pieza de colección.

Lamentablemente no existe un método que permita definir con precisión, exactitud y total objetividad cuál es el estado de conservación de una moneda.

Menciono esto porque muchas veces entre numismáticos de mucha experiencia existen diferencias de depreciación del estado de conservación de una moneda e incluso el mismo analista experto puede cambiar su opinión al volver evaluar el estado de ciertas piezas”.

\section{La Dolarización bajo condiciones iniciales frágiles}

(Beckerman \& Solimano, 2002)

"La elección de un sistema monetario por parte de un país es una decisión de largo alcance que, bajo circunstancias normales, debe ser precedida por un período de discusión interna sobre las ventajas y posibles desventajas de las distintas alternativas de régimen cambiario. Más aun, la adopción de una moneda extranjera para remplazar a la moneda local necesita estar acompañada de una adecuada preparación y de reformas legales en varios sectores de la economía. Un sólido sistema bancario, una situación fiscal sostenible y flexibilidad de 


\section{La dolarización en el Ecuador}

Vol. 1, núm. 5., (2017)

Xavier Francisco Flores Torres; Diógenes David Díaz Jiménez; Logan Radames Berni Morán

precios y salarios son condiciones económicas indispensables para poder realizar un proceso exitoso de dolarización.

La decisión de cuándo y cómo dolarizar (por ejemplo el momento de aplicarla y los pasos a seguir) es sin embargo un asunto de debate. Algunas per- 20 sanas consideran que la dolarización no necesita esperar a que las reformas estructurales se den; y creen, al contrario, que la dolarización puede acelerar todo el proceso de adopción de reformas económicas estructurales (8). Como se señaló anteriormente, cuando Ecuador anunció la dolarización en enero del año 2000 no existían las adecuadas condiciones fiscales y financieras, ni las prácticas contables que un sistema dolarizado requiere. Está claro que la dolarización no fue una decisión tomada bajo condiciones controladas para asegurar su éxito. Es más, fue una acción audaz para revertir una situación cercana a la hiperinflación y detener la fuga masiva de capitales, provocadas por un largo período de inestabilidad monetaria. Además, como ya se mencionó, el presupuesto fiscal tuvo un elevado déficit a lo largo del año previo a la dolarización; y el Estado intervino a gran parte del sistema bancario, incluyendo instituciones con patrimonio neto negativo".

\section{Política económica contractiva}

(Davalos Guevara , 2004)

Con la dolarización en términos práctico, se han eliminado las políticas monetarias y cambiaría como instrumentos de estímulos o desestimulo del crecimiento económico y de estabilización del nivel de precios. La política fiscal ha quedado como la única encargada del control de inflación, la misma que en las dos últimas décadas ha sido generada principalmente por exceso de gasto fiscal o por exceso de emisión monetaria. 


\section{La dolarización en el Ecuador}

Vol. 1, núm. 5., (2017)

Xavier Francisco Flores Torres; Diógenes David Díaz Jiménez; Logan Radames Berni Morán

\section{Eficiencia Microeconómica}

(Lopez, 2010)

Se registran tres condiciones básicas para que la dolarización sea favorable a una economía:

a) El grado de flexibilidad del mercado de factores de la producción.

b) El grado de apertura de una economía.

c) El grado de diversificación de la producción nacional.

Mientras más flexible, abierto y diversificado sea un país, mayores beneficios conseguirá de la dolarización. En el caso ecuatoriano, la evolución del comercio exterior depende de los precios internacionales, la devaluación monetaria y del PIB externo; mientras que, en el mercado laboral, subsisten los contratos sindicales que consiguen la estabilidad laboral y niveles mínimos salariales que no están ligados a la productividad del trabajador.

\section{Los depósitos en dólares en el extranjero}

(Gastambide, 2010) Afirma:

“La constitución por parte del público de depósitos en dólares en el extranjero es resultante del fenómeno amplio de la fuga de capitales que se acerca del concepto de hot money 


\section{La dolarización en el Ecuador}

Vol. 1, núm. 5., (2017)

Xavier Francisco Flores Torres; Diógenes David Díaz Jiménez; Logan Radames Berni Morán definido por Cuddington (1986). Se puede anotar que: la sustitución de un activo en moneda nacional por un depósito en dólares en el extranjero reduce del mismo importe la masa monetaria nacional, mientras que un depósito en dólares en el sistema bancario nacional la deja sin cambios. Estas fugas de capitales reducen pues la intermediación financiera.

En la literatura, las medidas de la dolarización parcial omiten a menudo los depósitos en dólares en el extranjero. Dos razones principales pueden explicar este estado de hecho. En primer lugar, hay un problema de disponibilidad de los datos sobre estas series que no son el objeto de un registro sistemático por parte del FMI o las instituciones nacionales. En segundo lugar, en un marco institucional liberalizado y estable en el tiempo, la consideración de estos depósitos puede perder su importancia.

En efecto, si los depósitos en dólares en un sistema bancario liberalizado y seguro son autorizados desde un tiempo suficiente, la existencia de los depósitos en dólares en el extranjero puede ser omitido para medir la dolarización parcial ya que los dos tipos de depósitos evolucionarían en el mismo sentido.

Por consiguiente, la parte relativa de los depósitos en dólares en el sistema bancario nacional puede ser suficiente para disponer de una medida correcta de la dolarización parcial en una economía. En cambio, si el contexto institucional está reprimido y/o inestable la consideración de los depósitos en el extranjero se vuelve a menudo indispensable, sobre todo en ausencia de datos sobre los billetes en dólares" (p.60).

\section{La trampa de la dolarización}




\section{La dolarización en el Ecuador}

Vol. 1, núm. 5., (2017)

Xavier Francisco Flores Torres; Diógenes David Díaz Jiménez; Logan Radames Berni Morán

(Acosta, 2012) Afirma: "Ecuador sorprendió al mundo en enero del 2000. Con la dolarización oficial plena de su economía. Fue el primer país de América latina que sacrifico su moneda nacional e introdujo una moneda extranjera el curso legal completo. Panamá era, hasta entonces, el único país que había asumido el dólar norteamericano como resultado de una imposición externa a poco de su separación de Colombia en 1903. Al inicio del tercer milenio, un año después Ecuador, dos países centroamericanos como El Salvador y Guatemala, con diversos ritmos se encaminaron hacia la dolarización plena de sus economías” (p.2).

En este contexto se profundizara la discusión sobre la dolarización o no las economías de América latina, especialmente en economía que atraviesan una situación extremadamente crítica, como argentina. Y como van las cosas, en la mayoría de casos, " la decisión final sobre la dolarización plena no se impondrán ni se rechazara por los designios de la razón, sino que responderán a la dinámica derivada de la armazón de los interés políticos hegemónicos y de la lógica del capital a escala internacionalmente, respaldados por las cúpulas dominantes de los países Latinoamericano“ en otra palabras la dolarización sería más el resultado de decisiones y angustias políticas antes que la consecuencia de reflexiones técnicas.

Desde esta perspectiva cabe analizar sus alcances y por cierto, sus limitaciones. A la dolarización, en consecuencia, no hay como ubicarla únicamente en el campo económico, hay que estudiarla como una herramienta de uso múltiple en varios ámbitos.

\section{Dinero electrónico}

(Vega, 2012) Afirma: "Se define como dinero electrónico al valor o producto pre-pagado, donde el registro de los fondos o valor disponible al consumidor (que se puede utilizar para 


\section{La dolarización en el Ecuador}

Vol. 1, núm. 5., (2017)

Xavier Francisco Flores Torres; Diógenes David Díaz Jiménez; Logan Radames Berni Morán

pagos) está almacenado en dispositivos electrónicos, tales como los monederos electrónicos (tarjetas pre-pago), los teléfonos celulares. Se utiliza como medio de pago en transacciones de bajo valor con entidades diferentes al emisor del dinero electrónico. El dinero electrónico es una innovación que puede mejorar la inclusión financiera, pues acerca los servicios de pagos a las personas de bajos ingresos y que viven alejadas de zonas urbanas, sin necesidad de crear una infraestructura física de agencias".

Los pagos que podrían realizarse con dinero electrónico incluyen:

- De individuo a individuo.

- De individuos a negocio, por compras de bienes o servicios.

- De empresas a individuos; por ejemplo, salarios.

Cuando un ciudadano quiera obtener dinero electrónico va cercarse a un sitio de transacción que puede ser una agencia bancaria, agencia de entidad financiera o, una cadena de almacenes, el dinero electrónico está diseñado para que los puntos de transacción puedan estar en todas partes.

Análisis FODA

Revista Científica Mundo de la Investigación y el Conocimiento. 1(5). pp. 601-624 


\section{La dolarización en el Ecuador}

Vol. 1, núm. 5., (2017)

Xavier Francisco Flores Torres; Diógenes David Díaz Jiménez; Logan Radames Berni Morán

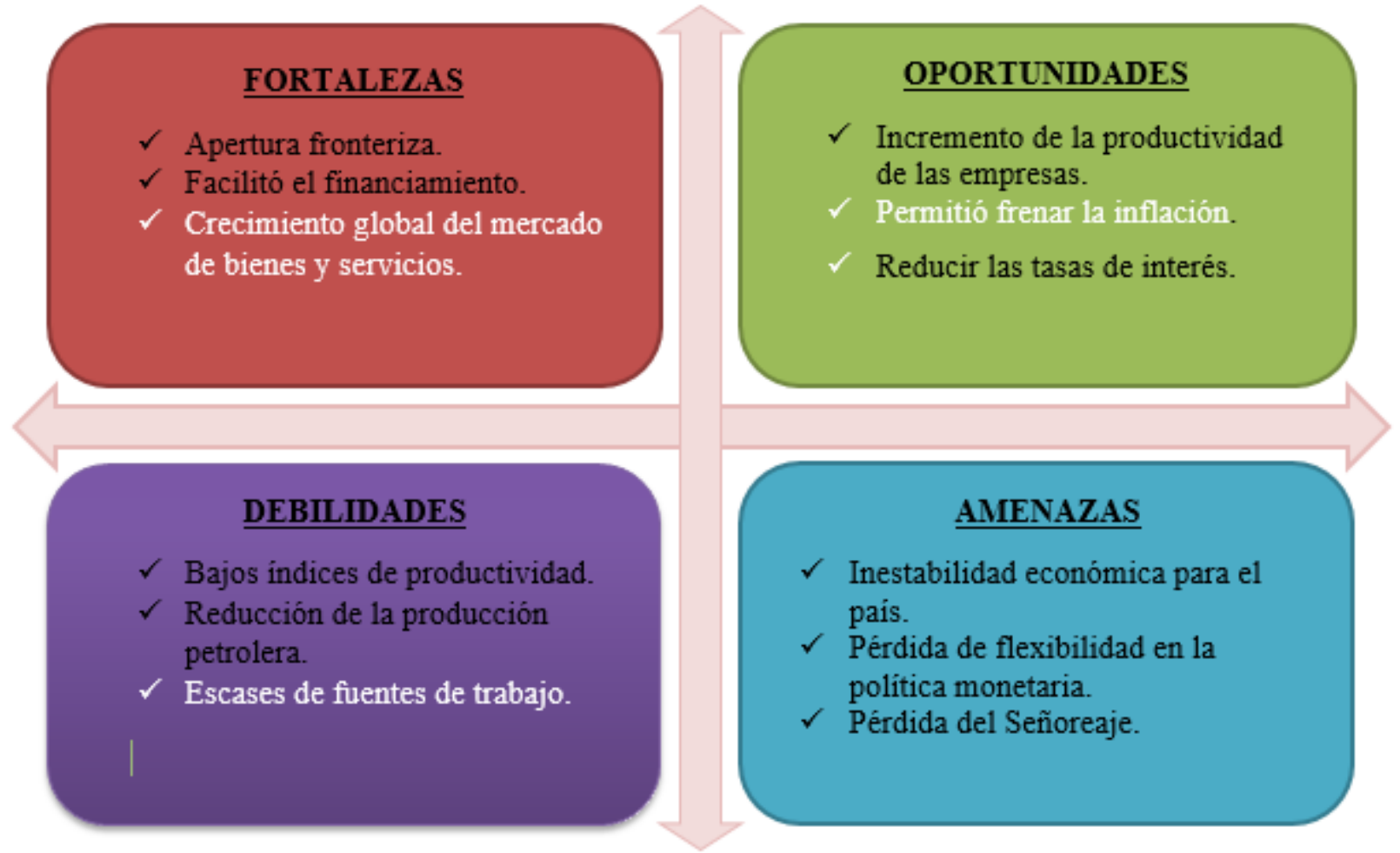

\section{Comparación de la dolarización en Ecuador y Salvador}

Los primeros países dolarizados de América latina fueron, el Salvador y Ecuador; las causas que llevaron a estos países a dolarizarse fueron diferentes, el Ecuador estaba atravesando por una crisis financiera y una economía a las puertas de la hiperinflación, mientras que el Salvador no estaba afrontando una crisis económica y la inflación del país estaba controlada.

(Swiston, 2011) Afirma: "La decisión de El Salvador de convertir el dólar estadounidense en moneda oficial se hizo en el contexto de sólidos fundamentos macroeconómicos. La inflación era baja y estable, la economía estaba creciendo, las deudas públicas y externas eran manejables y no había turbulencia en el sistema bancario. 


\section{La dolarización en el Ecuador}

Vol. 1, núm. 5., (2017)

Xavier Francisco Flores Torres; Diógenes David Díaz Jiménez; Logan Radames Berni Morán

Los argumentos para la dolarización se basaron en cómo estrecharía los vínculos con la economía de Estados Unidos y estimularía la inversión extranjera, el comercio y el crecimiento económico" (p.3).

\section{¿Qué pasaría si se implementa el dinero electrónico en Ecuador?}

Si se estableciera el dinero electrónico estaría administrado por el banco central del ecuador sin fines de lucros, lo que garantizará bajos costos, una alta capacidad democráticamente para todos los ecuatorianos.

Si se implementa el dinero electrónico en el Ecuador será más eficiente, ya que el Banco Central del Ecuador para hacer la transacción el ciudadano entregará un billete y a cambio del billete el Banco Central le cargará el valor del billete en forma de dinero electrónico en el teléfono celular, quiere decir que el dinero electrónico esta 100\% respaldado en dólares físicos.

Además, el dinero electrónico traerá ventajas como; hacer transferencias de pago más rápido a través de los teléfonos celulares, ya que no es necesario que tenga internet y tampoco se necesita que la persona que utilice el dinero electrónico tenga una cuenta bancaria o una cuenta en una entidad financiera.

\section{Metodología aplicada}

La dolarización como una investigación socioeconómica la realizamos para detallar su incidencia económica en Ecuador y así poder especificar de qué manera afectó a la sociedad la modificación del sistema monetario en aquella época. 


\section{La dolarización en el Ecuador}

Vol. 1, núm. 5., (2017)

Xavier Francisco Flores Torres; Diógenes David Díaz Jiménez; Logan Radames Berni Morán

Para alcanzar el objetivo de la presente investigación fue necesario aplicar técnicas adecuadas que nos permitió identificar claramente el tipo, diseño, y la modalidad de la investigación, además se aplicaron métodos apropiados para el análisis de los resultados, a continuación se detallan los procesos investigativos aplicados en el presente artículo científico.

El tipo de investigación aplicado en este artículo son: exploratoria, descriptiva, explicativa y experimental.

\section{- Exploratoria:}

Es exploratorio porque recolectamos datos en diferentes ciencias como son la revisión bibliográfica especializada en el caso de la dolarización, con el fin de obtener una crítica interna y externa sobre lo investigado.

(Arias, 2012) Afirma: “La investigación exploratoria es aquella que se efectúa sobre un tema u objeto desconocido o poco estudiado, por lo que sus resultados constituyen una visión aproximada de dicho objeto, es decir, un nivel superficial de conocimientos” (p.23).

\section{- Descriptivo:}

Es representativo porque detallaremos la información obtenida en los diferentes artículos científicos; en la cual se especificarán las ventajas y desventajas de la dolarización.

(Bernal C., 2010) Afirma: "Se reseñan las características o rasgos de la situación o fenómeno objeto de estudio" (p.110).

\section{- Explicativa}




\section{La dolarización en el Ecuador}

Vol. 1, núm. 5., (2017)

Xavier Francisco Flores Torres; Diógenes David Díaz Jiménez; Logan Radames Berni Morán

Es especificativa porque se encarga de buscar el porqué de los hechos mediante el establecimiento de las ventajas y desventajas de la dolarización. En este sentido, los estudios explicativos pueden ocuparse tanto de la determinación de las causas como de sus consecuencias.

(Fidias, 2012) Afirma: "La investigación explicativa se encarga de buscar el porqué de los hechos mediante el establecimiento de relaciones causa-efecto. En este sentido, los estudios explicativos pueden ocuparse tanto de la determinación de las causas (investigación post facto), como de los efectos (investigación experimental), mediante la prueba de hipótesis. Sus resultados y conclusiones constituyen el nivel más profundo de conocimientos” (p.26).

\section{○ Experimental}

Es una investigación empírica porque nos ayuda a recolectar información de las diferentes ciencias bibliográficas, donde encontraremos sus falencias, como: Pérdida del señoreaje, Pérdida de flexibilidad en la política monetaria, alza de los precios, entre otros, y mediante esto podremos ver la mejor manera de que el gobierno adapte nuevas propuestas para el mejoramiento del país.

(Arias, 2012) Afirma: "La investigación experimental es un proceso que consiste en someter a un objeto o grupo de individuos a determinadas condiciones o tratamientos para observar los efectos o reacciones que se producen" (p.33).

En conclusión, la inestabilidad monetaria y la falta de credibilidad en el sucre repercutieron en la solvencia del sistema financiero del país, ya que el presidente de la república del Ecuador el Abg. Jorge Jamil Mahuad dio inicio a este nuevo sistema de dolarización con el fin de frenar la tremenda volatilidad y detener la creciente inflación que amenazaba en 


\section{La dolarización en el Ecuador}

Vol. 1, núm. 5., (2017)

Xavier Francisco Flores Torres; Diógenes David Díaz Jiménez; Logan Radames Berni Morán

convertirse en hiperinflación, pero este nuevo sistema, no garantizó en el futuro el fortalecimiento de la economía del país.

Este cambio drástico tuvo un efecto inflacionario negativo para la economía del país, aumentando la tasa de interés y los precios de bienes, productos y servicios, además causó inestabilidad económica, perdida de flexibilidad en la política monetaria y pérdida del señoreaje.

\section{Conclusiones.}

El país debe utilizar todos los mecanismos posibles incluyendo la legislación bancaria, para la reactivación productiva, por tanto, si el país cuenta con fondos monetarios deberían usarlos para evitar que se siga deteriorando la economía del país.

Al adoptar el dólar como moneda nacional se redujeron las dimensiones de la política monetaria al límite de manejar por parte del Banco Central solo dinero fraccionario, apreciando la decadencia que se ha venido presentando en la sostenibilidad de este sistema aun cuando esta ha presentado cierta estabilidad en el mercado de divisas, es por tal motivo buscar alternativas financieras que permitan mantener este proceso en el largo plazo a través de políticas públicas que incentiven a que el sector productivo pueda ser más competitivo, políticas que permitan atraer capitales con la Inversión Extranjera Directa, etc.

Hay que controlar el ingreso y salida del dólar para la estabilidad financiera de nuestra economía, determinando mecanismos de control que conlleven a la regulación de la divisa y no solo depender de un Banco Central que cada vez más carece de funciones. 


\section{La dolarización en el Ecuador}

Vol. 1, núm. 5., (2017)

Xavier Francisco Flores Torres; Diógenes David Díaz Jiménez; Logan Radames Berni Morán

Debe existir la participación por parte del Estado con la creación de una ley orgánica de la producción y precios, que contenga normas y políticas de control sobre la producción, calidad, cantidad, peso y precios de bienes y servicios.

\section{Bibliografía.}

Acosta, A. (2012). Dolarizacion en el Ecuador: Antecedentes, relaidad y prespectivas. Guayaquil: Universidad de Guayaquil.

Beckerman, P., \& Solimano, A. (2002). Crisis y dolarización en el Ecuador. Quito: Observatorio Social del Ecuador.

Davalos Guevara , M. (2004). La dolarizacion en el Ecuador ensayo y crisis. Quito: ABYA AYALA.

Fidias, A. (2012). El proyecto de la investigacion . Caracas: EPISTEME .

Gastambide, A. (2010). El camino hacia la dolarización en Ecuador. Quito: Flacso-Ecuador.

Lopez, J. (2010). Perspectiva de la aplicacion de un modelo economico del Ecuador. Guayaquil: Universidad de Guayaquil.

Marco, N. (2008). Dolarización oficial y regímenes monetarios en el Ecuador. Guayaquil: Calamelo.

Reyes, R. (2011). Numismatica Ecuatoriana Evololucion y coleccionismo. Quito: Municipio de Quito.

Santos, T. (21 de 01 de 2015). Quienes promovieron la dolarización en el Ecuador. Vistazo.

Swiston, A. (2011). OFFICIAL DOLLARIZATION AS A MONETARY REGIME. IMF WORKING PAPER, 3-10.

Vega, M. (2012). Dinero electronico: innovacion en pago al por menor para promover la inclusión. Revista Moneda, 153(1), 15-18. 


\section{La dolarización en el Ecuador}

Vol. 1, núm. 5., (2017)

Xavier Francisco Flores Torres; Diógenes David Díaz Jiménez; Logan Radames Berni Morán 